\title{
APPENDECTOMY IN THE TIMES OF COVID-19: COMPARATIVE STUDY OF TWO GROUPS OF PATIENTS BETWEEN SIMILAR PERIODS OF TIME - 2019 VS 2020
}

\author{
C.Ungureanu ${ }^{1}$, R. Mirică ${ }^{1}$, R. Iosifescu ${ }^{1}$, M. Zamfir ${ }^{1}$, M. Mardare ${ }^{1}$, N. Iordache ${ }^{1}$, O. Ginghină ${ }^{1}$ \\ ${ }^{1}$ Saint John Emergency Hospital, General Surgery Department, Bucharest, Romania
}

\begin{tabular}{l} 
ORIGINAL \\
PAPER \\
\hline
\end{tabular}

DOI: $10.33695 /$ rojes.v2i1.18

Accepted: 07.05.2020
Corresponding author:

Radu Mirică

miricarm@yahoo.com

\section{Abstract}

Acute pathology of the cecal appendix - appendicitis, is a condition that does not take into account the pandemic period. The aim of this study is to retrospectively analyze the relationship of care for two groups of patients who underwent appendectomy in COVID-19 period and one year before, same period of time, in emergency hospital service. We performed a retrospective analysis on the patients admitted in our surgery center by comparing two groups for each period analyzed: group A, for the period March-May 2019 and group B for the period March-May 2020 (corresponding to COVID19 pandemic). We compared the groups analyzing features that prove the change in age, incidence, grade (severity) of appendicitis, delay of surgery, length of surgery, postoperative complications and hospitalization time. CT scan was made for each patient. In the group B, PCR COVID-19 testing was made (all patients were negative for COVID-19). Our study consisted of 52 patients, group A-32 patients $(61.53 \%)$ and group B-22 patients $(38.47 \%)$. The Covid-19 pandemic influenced the incidence of appendicitis and we noted a delayed presentation which led to more complicated appendicitis than same period of the previous year. The impact also was noted on length of surgery, due to use of PPE (personal protective equipment) and also modified anatomy of the region related to inflammation. The severity of appendicitis was higher in the COVID-19 period when compared to 2019 similar period of time. Further research is required to draw more conclusions on this period.

Keywords: appendectomy, covid-19, delay of surgery, appendicitis

\section{Introduction}

Acute appendicitis represents one of the most common emergency in a General Surgery Emergency Unit. The standard treatment for appendicitis is surgery, but some prefer using conservative therapy with good results in selected cases [1]. During the outbreak of COVID-19 pandemic, the incidence in abdominal emergencies declined. COVID-19 was identified for the first time in Wuhan, China in December 2019 and declared a global pandemic on 11 March 2020. Our study is related to the period March-May in comparison with the same period of 2019. 


\section{Material and methods}

We analyzed patients that presented in emergency care unit and had undergone appendectomy as a primary treatment. CT was made for diagnosis.

The primary outcome of the study was to compare the influence of COVID-19 pandemic on the treatment of acute appendicitis. Also, we studied the change in severity and surgery time for the patients in the two periods.

There were two groups made: Group A - represents patients admitted and operated in 2019, period March-May, whilst group B consists of patients operated in the corresponding period in 2020.

Statistical analysis was performed with IBM SPSS $23 \AA$ for Windows $®$, with a pvalue $<0.05$ considered significant.

\section{Results}

For the group A, mean age was 40.63 $( \pm 16.36)$ and for group B a value of 39.80 $( \pm 14.67)$ and we noted no significant difference in the distribution of age of the patients $(\mathrm{p}=0.855)$. Regarding the sex ratio, we noted predominance of men, with a male: female ratio of 1.46:1 for group A and 3:1 for group B; there was no significant difference in the sex distribution.

After admission, investigations were made and also antibiotic treatment was initiated. This resulted in a delay to surgery, variable measured in hrs. The overall mean for this measured time was $9.42 \mathrm{hrs}( \pm 10.52)$. For group A, the value was lower $-7.94 \mathrm{hrs}$ $( \pm 8.747) \mathrm{hrs}$ and higher for group B -10.90 hrs $( \pm 12.58)$; there was no significant difference between groups regarding the delay to surgery $(\mathrm{p}=0.321)$. When comparing between the groups, there was no significant difference in the length of hospitalization; the mean of the two groups reported was 4.84 days $( \pm 4.11)$. We listed the results in table 1 .
In acute appendicitis, complications are related to perforation of the gangrenous lesions of appendix, peritonitis and abscess. The severity of appendicitis was assessed through a set of 5 grades of appendicitis: uncomplicated, peritonitis, perforation, abscess, tumor (the last four categories representing the complicated appendicitis) see table 2.

For group A, uncomplicated cases were predominant (19 cases $-76 \%$ of total) whilst for group B the complicated cases represent majority (14 cases $-76 \%$ of total). In table 2 is listed the differences of the two groups. We noted a level of statistical significance between the two groups $(\mathrm{p}=0.038)$ regarding the uncomplicated vs complicated appendicitis. So, we can consider that the severity of appendicitis was higher in the group B, i.e., COVID-19 period (fig.1).

Regarding surgical approach, our surgical Centre follows the idea that appendectomy is the main treatment for acute appendicitis. Also, our gold standard approach for acute appendicitis is laparoscopic appendectomy. In 2019, following these guidelines there was a predominance of laparoscopic type of appendectomy (29 cases $-90.25 \%$ of total, with 3 conversions or open approach). For 2020 period, a similar trend was noted $(75 \%$ of total). There was no statistical difference noted between groups regarding the type of surgery performed $(\mathrm{p}=0.235)$.

Conversion to open surgery was also compared and we observed 2 cases in the group B (3.8\%), both cases with difficulties in dissection and isolation of the appendix due to inflammation and abscesses; also there was no statistical difference noted between groups.

Length of surgery was also analyzed. Considering our surgical center's experience in laparoscopic emergency surgery and colorectal field, the overall mean was 93.48 $( \pm 29.66)$ minutes. For group A, the time was shorter - $80.47( \pm 23.60)$ mins, whilst for 
group B this time was prolonged - 106.50 $( \pm 35.72)$ mins. This was also due to the difficulties of handling everything in the additional COVID protection equipment. We noted significant difference between the two groups $(\mathrm{p}=0.003)$.

To compare the postoperative complications, we created 6 categories as listed below in table 3 . We observed more wound seroma and infection in the group B when compared to group A ( 2 cases vs none).

Also, in the group B there were 2 intestinal obstructions postoperatively $(3.8 \%$ of total), one managed with conservative treatment and the other was reoperated. Two deaths $(3.8 \%$ of total) were reported, one for each group.
The first case in the group A was a 57 years male, presented with perforated appendicitis and SOFA-2 score. The surgery was open, but few days after he developed intestinal obstruction, which was reoperated. Subsequently, the MSOF installed lead to cardiac arrest and death.

The case in the group B was a 36 male, also presented with perforated appendicitis and aggravated MSOF. He was managed via laparotomy, but the postoperative course was marked by cardiac arrest few hours after surgery.

There was no significant difference between groups regarding postoperative complications $(\mathrm{p}=0.392)-$ see fig. 2 .

\begin{tabular}{lllll}
\hline & \multicolumn{1}{c}{ Total } & \multicolumn{1}{c}{ Group A } & \multicolumn{1}{c}{ Group B } & p-value \\
\hline Variable & $\mathrm{n}=52$ & $\mathrm{n}=32$ & $\mathrm{n}=20$ & \\
\hline Age (years) & $40.21( \pm 15.51)$ & $40.63( \pm 16.36)$ & $39.80( \pm 14.67)$ & 0.855 \\
\hline Sex & & & & \\
\hline Male & 34 & 19 & 15 & 0.249 \\
\hline Female & 18 & 13 & 5 & 0.321 \\
\hline Delay to surgery (hours) & $9.42( \pm 10.52)$ & $7.94( \pm 8.747)$ & $10.90( \pm 12.58)$ & 0.003 \\
\hline Length of surgery (min) & $93.48( \pm 29.66)$ & $80.47( \pm 23.60)$ & $106.50( \pm 35.72)$ & 0.447 \\
\hline Length of hospitalization (days) & $4.845( \pm 4.11)$ & $5.34( \pm 5.313)$ & $4.35( \pm 2.907)$ & \\
\hline Type of appendectomy & & & & 0.235 \\
\hline Open & $8(15.4 \%)$ & $3(9.4 \%)$ & $5(25 \%)$ & $15(34.1 \%)$ \\
\hline Laparoscopic & $44(84.6 \%)$ & $29(65.9 \%)$ & & \\
\hline
\end{tabular}

Table 1 - Comparison between the two groups in the study (group A for the 2019 period and group $B$ for the 2020 period), presented with acute appendicitis in our center

\begin{tabular}{lccc}
\hline Grade of appendicitis & Total & Group A & Group B \\
\hline Uncomplicated & $25(48.1 \%)$ & $19(76 \%)$ & $6(24 \%)$ \\
\hline Peritonitis & $14(26.9 \%)$ & $5(35.7 \%)$ & $9(64.3 \%)$ \\
\hline Perforation & $6(11.5 \%)$ & $4(66.7 \%)$ & $2(33.3 \%)$ \\
\hline Abscess & $5(9.6 \%)$ & $4(80 \%)$ & $1(20 \%)$ \\
\hline Tumor & $2(3.8 \%)$ & 0 & $2(100 \%)$ \\
\hline$p=0.038$ & & &
\end{tabular}

Table 2 - Comparison between the two groups regarding the grade of appendicitis (complicated vs uncomplicated) 
Appendectomy in the times of COVID-19: comparative study of two groups of patients between similar periods of time - 2019 vs 2020

\begin{tabular}{llll}
\hline Postop. Complications & Total & Group A & Group B \\
\hline None & $45(86.5 \%)$ & $28(62.2 \%)$ & $17(37.8 \%)$ \\
\hline intestinal obstruction & $2(3.8 \%)$ & 0 & $2(100 \%)$ \\
\hline wound infection & $1(1.9 \%)$ & 0 & $1(100 \%)$ \\
\hline wound seroma & $1(1.9 \%)$ & 0 & $1(100 \%)$ \\
\hline Clostridium difficile enterocolitis & $1(1.9 \%)$ & $1(100 \%)$ & 0 \\
\hline cardiac arrest & $2(3.8 \%)$ & $1(50 \%)$ & $1(50 \%)$ \\
\hline$p=0.392$ & & &
\end{tabular}

Table 3 - Comparison between the two groups regarding the postoperative complications after appendectomy

\section{Discussion}

COVID-19 pandemic impacted our practice and treatment for the vast majority of abdominal pathologies. The conduct of diagnosis and treatment during the pandemic period was modified due to the necessary of protection and testing measures. Thus, the difficulty of the surgical interventions was increased by the time allocated to the equipment process, respectively by the inconvenience of carrying out a difficult intervention in the special personal protection equipment.

The incidence of acute appendicitis decreased, and some studies report this fact $[2,3]$. In our study, for the group B, we noted fewer patients when comparing to group A. Indeed, the COVID-19 changed the number of presentation at emergency department, it is possible that many patients with mild grades of appendicitis spontaneously or with automedication came to resolution.

Regarding age and sex, male predominance was noted in both groups and we found no significant difference between the groups studied. Few reports in literature conclude the same [2,11].

Laparoscopic appendectomy is considered a basic operation, although it can be an intraoperative challenge [4] if the time from onset to presentation is long and thus its severity much higher [3,5]. Severe presentation with multiple organ failure and SOFA score $>2$ require increased attention and rapid surgical intervention.

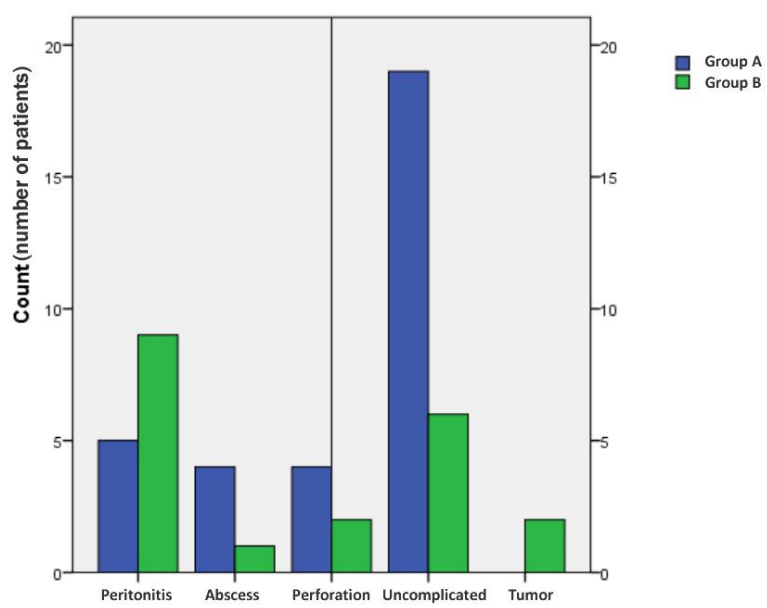

Figure 1 - Comparison between the two groups regarding the grade of appendicitis. (blue bar Group A, green bar - Group B). There is significant difference between groups, in the group $A$ there is a predominance of uncomplicated grades of appendicitis whilst in the group B complicated forms are higher. (X axis is for the grade of appendicitis and $Y$ axis for the number of cases).

There was no significant difference between groups regarding the delay to surgery $(\mathrm{p}=0.321)$, with a mean of $9.42 \mathrm{hrs}( \pm 10.52)$. We usually perform early appendectomy (i.e. - under $12 \mathrm{hrs}$ delay appendectomy). There are studies that show performing of appendectomy within 24 hrs after presentation does not prolong hospitalization time and the rate of complications, but delayed appendectomy after $24 \mathrm{hrs}$ from presentation does increase the complications [6]. 


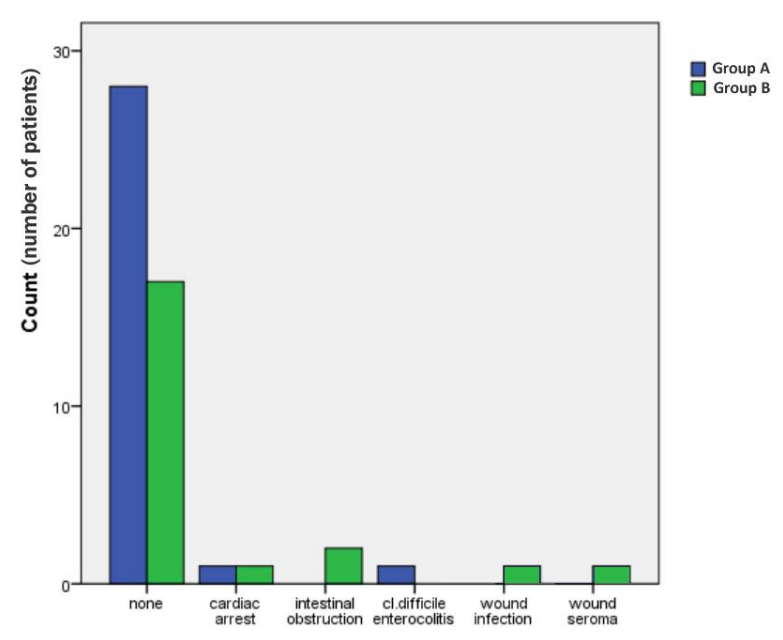

Figure 2 - Comparison between the two groups regarding the postoperative complications. (blue bar - Group A, green bar - Group B). We note the predominance of intestinal obstruction and wound complications for the group $B$. (X axis is for the postoperative complications and $Y$ axis for the number of cases).

For the same period of 2020, in the pandemic era of COVID-19, there were some facts we noted:

- For the patients without shock (SOFA score $<2$ ) we initiated conservative treatment and when the COVID-19 test was ready, we did laparoscopic appendectomy, general surgery guides suggesting not using laparoscopic approach in COVID-19 positive patients [9];

- Complicated acute appendicitis was operated in emergency scenario in couple of hours after presentation, in PPE and surgeons opted for open approach [10];

- More complicated cases of acute appendicitis were observed compared to 2019 period, but overall ratio was similar when comparing uncomplicated vs complicated total number of both groups.

The results present level of statistical significance between the two groups $(\mathrm{p}=0.038)$ regarding the uncomplicated vs complicated appendicitis. Possibly due to the covid-19 outbreak, patients have chosen to delay presentation to the emergency department - anxiety and fear of transmission patient-to-patient was high in the period of time analyzed in group B.

Also, there is evidence that advocate that delaying presentation to hospital increases the risk of perforated appendicitis [7]. Interestingly, studies that have separately studied the incidence of complicated vs noncomplicated appendicitis have inconsistently reported that this incidence is changing over time [8].

Also, there are facts that sustain the role of antibiotics in treatment of acute appendicitis for selected patients, depending on CT imaging and clinical picture $[6,8]$.

Expanding the results, in relation with the difference between the groups regarding complicated appendicitis, we found that length of surgery increased in COVID-19 times. Some studies did not show this difference [1,2]. Protection measures and usage of PPE can justify the results of our study regarding the time of surgery.

\section{Conclusions}

The COVID-19 pandemic influenced the incidence of appendicitis and we noted a delayed presentation which led to more complicated appendicitis than same period of the previous year.

The impact we also noted was on length of surgery, due to use of PPE (personal protective equipment) and also modified anatomy of the region related to inflammation.

The severity of appendicitis was higher in the COVID-19 period when compared to 2019 similar period of time. Further research is required to draw more conclusions on this period of time.

Conflict of interest: All authors declare that they have no conflict of interest. 
Appendectomy in the times of COVID-19: comparative study of two groups of patients between similar periods of time - 2019 vs 2020

\section{References}

[1]O'Connell EP, White A, Cromwell P et al. Non-operative treatment of appendicitis: public perception and decision making. Ir $\mathrm{J}$ Med Sci 2018; 187: 1029-38.

[2]Hansson J, Korner U, Khorram-Manesh A et al. Randomized clinical trial of antibiotic therapy versus appendicectomy as primary treatment of acute appendicitis in unselected patients. Br J Surg 2009; 96: 473-81

[3]Tiwari MM, Reynoso JF, Tsang AW, Oleynikov D. Comparison of outcomes of laparoscopic and open appendectomy in management of uncomplicated and complicated appendicitis. Ann Surg 2011;254:927-32.

[4]María Velayos, Antonio Jesús MunozSerrano, Karla Estefanía-Fernández, Ma Carmen Sarmiento Caldas, Lucas Moratilla Lapena, Manuel López-Santamaría y Juan Carlos López-Gutiérrez. Influencia de la pandemia por coronavirus 2 (SARS-Cov-2) en la apendicitis aguda. Servicio de Cirugía Pediátrica. Hospital Universitario La Paz, Madrid, Espana. Annales de Pediatria, 11 May 2020.

[5]American College of Surgeons. COVID-19 guidelines for triage of emergency general surgery patients. https:// www.facs.org/covid19/clinical-guidance/elective-case/eme rgency-surgery
[6]Giraudo G, Baracchi F, Pellegrino L, Dal Corso HM, Borghi F. Prompt or delayed appendectomy? Influence of timing of surgery for acute appendicitis. Surgery Today, 30 Aug 2012, 43(4):392-396 [7]Kearney D, Cahill RA, O'Brien E, Kirwan WO, Redmond HP (2008) Inffluence of delays on perforation risk in adults with acute appendicitis. Dis Colon Rectum 51(12):18231827.

[8]Livingston EH, Woodward WA, Sarosi GA, Haley RW. Disconnect between incidence of nonperforated and perforated appendicitis: implications for pathophysiology and management. Ann Surg. 2007 Jun; 245(6):886-92.

[9]Royal College of Surgeons. Updated general surgery guidance on COVID-19. https://www.rcseng.ac.uk/coronavirus/ jointguidance-for-surgeons-v2/

[10]Brat GA, Hersey SP, Chhabra K, Gupta A, Scott J. Protecting surgical teams during the COVID-19 outbreak: a narrative review and clinical considerations. Ann Surg 2020. [11]M. Collarda, Z. Lakkis b, J. Loriauc, D. Mege d, C. Sabbaghe,f, J.H. Lefevrea, L. Maggiori G. Crise sanitaire liée au COVID19 : modalités du traitement de l'appendicite aiguë non compliquée de l'adulte par antibiothérapie seule comme alternative à l'appendicectomie. Journal de Chirurgie Viscérale (2020) 157, S33-S43. 